\title{
ENURESIS: ARE PUNISHMENTS USEFUL FOR TREATMENT AND FOR CHILD DEVELOPMENT?
}

\author{
P. Ferrara ${ }^{1}$, R. Autuori², M. Di Giuseppe ${ }^{2}$, A. Sbordone' 1 , M. Amato², G. Franceschini², F. \\ Di Ruscio², F. Fiori Nastro², E. Di Giacomo², D. Saitta². \\ 1 Università Cattolica del Sacro Cuore, Institute of Pediatrics, Rome, Italy. \\ 2Università Campus Bio-Medico, Service of Pediatrics, Rome, Italy.
}

\section{Background and Aims}

A group of children suffering from Nocturnal Enuresis (NE) does not respond completely to current therapies. Bedwetting became unacceptable for numerous parents, to the point of blaming their children and adopting punitive means of coping. Parental corporal punishment often occurs in association with other discipline techniques such as time-out, withdrawal of privileges and verbally and physically violent behaviors.

The aim of this study is to investigate how the punishments in enuretic children can influence therapy response.

\section{Methods}

We administered a questionnaire to 218 enuretic children and their families at the end of the clinical evaluation.

\section{Results}

The questionnaires show that $12.4 \%$ $(27 / 218)$ of enuretic children have been punished at least once. Admonishment has been used in $70.4 \%(19 / 27)$ of cases, depriving of sleep in $40.7 \%(11 / 27)$ of cases, mildly beating in $11.1 \%(3 / 27)$ of cases, leaving the child wet in $3.7 \%(1 / 27)$ of cases and other methods in $7.4 \%(2 / 27)$ of cases. Only $40.7 \%$ of punished children and $59.2 \%$ of not punished children attained full or partial response in terms of decreased number of wet nights.

\section{Conclusion}

The therapy of enuresis (behavioral and/or medicinal) depends on single patient, his/her family and compliance of both. Enuretic children should be made aware of the disease and of their active role in the healing process. Similarly parents should be apprised of the adverse effect of punishment on child development.
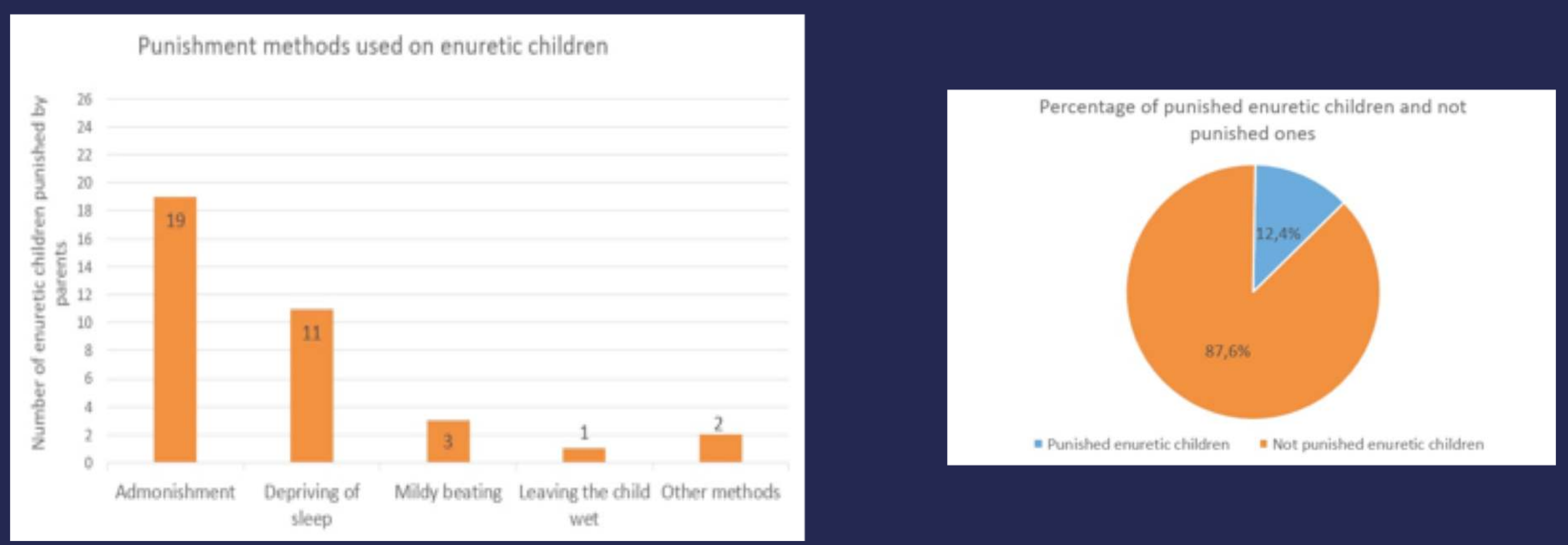